\title{
DIRECT ANTIATHEROGENIC ACTIVITY OF ISRADIPINE AND LACIDIPINE ON NEOINTIMAL LESIONS INDUCED BY PERIVASCULAR MANIPULATION IN RABBITS
}

\author{
E. DONETTI, R. FUMAGALLI, R. PAOLETTI and M. R. SOMA*
}

Institute of Pharmacological Sciences, University of Milan, Via Balzaretti 9, 20133 Milan, Italy

Accepted 2 April 1997

\begin{abstract}
The in vivo antiatherogenic activity of two calcium antagonists of the dihydropyridine class (isradipine and lacidipine) was investigated in a new experimental model. The proliferative lesion induced in the rabbit carotid artery was obtained by positioning a hollow silastic collar around the vessel. The neointimal formation was determined by measuring cross sectional thickness of intimal (I) and medial (M) tissue of fixed arteries obtained 14 days after collar placement. The effectiveness in inhibiting neointimal formation was assessed for isradipine $\left(0 \cdot 5,1\right.$ and $\left.4 \mathrm{mg} \mathrm{kg}^{-1} \mathrm{day}^{-1}\right)$ in normocholesterolemic (NC) animals and for lacidipine $(1,3$, and $10 \mathrm{mg} \mathrm{kg}^{-1}$ day $^{-1}$ ) in hypercholesterolemic (HC) rabbits. In $\mathrm{NC}$ control animals a neointimal formation was clearly detectable (I/M $0.53 \pm 0 \cdot 18, n=5$ ). In isradipine-treated groups $\mathrm{I} / \mathrm{M}$ ratios were significantly decreased $(0 \cdot 15 \pm 0.03,0 \cdot 12 \pm 0 \cdot 02,0 \cdot 1 \pm 0.02$ for the $0.5,1$ and $4 \mathrm{mg} \mathrm{kg}^{-1}$ day $^{-1}$ doses respectively). In $\mathrm{HC}$ rabbits the administration of cholesterol $1 \%$ mixed with food and drug treatment started either 60 days before collar insertion (pretreated group, HC60) or on the same day (non pretreated group, HC15) of the collar placement. Only the pharmacological pretreatment was effective in reducing neointimal formation $(0 \cdot 47 \pm 0 \cdot 02,0 \cdot 4$ \pm 0.09 , and $0.32 \pm 0.02$ for dose 1,3 and $10 \mathrm{mg} \mathrm{kg}^{-1} \mathrm{day}^{-1} v s 1 \cdot 1 \pm 0 \cdot 14$ in control animals). The inhibition of neointimal hyperplasia was much less evident in nonpretreated animals $(0 \cdot 7 \pm$ $0 \cdot 15,0.6 \pm 0 \cdot 18$ and $0.43 \pm 0.08$ for dose 1,3 , and $10 \mathrm{mg} \mathrm{kg}^{-1}$ day $^{-1}$ vs $0.72 \pm 0.2$ in control animals).

These results suggest a direct antiatherosclerotic effect of isradipine and lacidipine on neointimal hyperplasia induced in $\mathrm{NC}$ and $\mathrm{HC}$ pretreated rabbits independently of modulation of risk factors such as hypercholesterolemia and/or hypertension.
\end{abstract}

C 1997 The Italian Pharmacological Society

KEY WORDS: calcium antagonists, in vivo model, SMC proliferation.

\section{INTRODUCTION}

With the increasing knowledge on the pathogenesis of atherosclerosis it appears that prevention of cardiovascular disease will involve not only the correction of risk factors such as dyslipidemia or elevated arterial blood pressure but also the direct pharmacological control of atherogenic processes occurring in the arterial wall [1]. While the former approach is now definitely accepted in man, the latter still represents a 'therapeutic hope' which requires experimental and clinical confirmation. Recently, a great effort has been made in evaluating the direct effect of drug therapy on the arterial wall [2]. Abnormalities or dysfunctions of the vessel wall can favor vascular smooth muscle cell

\footnotetext{
*Corresponding author: Maurizio Soma, Institute of Pharmacological
Sciences, University of Milano, Via Balzaretti, 9, 20133 Milano,
Italy. *Corresponding author: Maurizio Soma, Institute of Pharmacological
Sciences, University of Milano, Via Balzaretti, 9, 20133 Milano,
Italy. Italy.
}

(SMC) migration from the media and proliferation within the intima, and increase lipid deposition or reduce lipid clearance from infiltrating monocytes. These processes trigger a cascade of events leading to the development of vascular disease [1-3].

Therapeutic interventions which interfere with early stages of atherosclerosis may improve the chances of halting and slowing the disease progression. Among drugs currently available for therapy of vascular disease calcium antagonists have been investigated extensively as antiatherogenic agents in a variety of in vitro and in vivo experimental models [2, 4-7]. Increases in intracellular calcium are a very basic biological signaling mechanism involving numerous processes, such as platelet activation, SMC migration and proliferation, and endothelial dysfunctions [1]. In in vivo models calcium antagonists protect against lesions induced by cholesterol feeding, endothelial injury, and experimental calcinosis [8-13]. The in vitro effects of these drugs on proC) 1997 The Italian Pharmacological Society 
cesses which play a role in the development of atherosclerotic lesions might help in explaining these results. For instance, several calcium antagonists inhibit SMC migration [14], the uptake of lipids by macrophages [15-18]. However, few attempts have been made to relate these in vitro effects to the complex changes which occur in the vessel wall. Recently, a model of carotid neointimal hyperplasia, mainly dependent on SMC migration and proliferation, has been developed $[19,20]$. Using this model we investigated the in vivo effect of two dihydropiridines, isradipine and lacidipine, on a vascular lesion mainly characterized by migration and proliferation of SMC induced by collar insertion around a carotid artery of $\mathrm{NC}$ and $\mathrm{HC}$ animals.

\section{MATERIALS AND METHODS}

\section{Study protocol}

New Zealand male rabbits $(n=60) \quad(2-2.5 \mathrm{~kg}$, Charles River, Calco, Italy) were used in this study. Animals were divided into the following groups and maintained in identical experimental conditions.

Normocholesterolemic animals.

Control group $(n=5)$.

Low dose isradipine $(n=5)$ : isradipine $0.5 \mathrm{mg} \mathrm{kg}^{-1}$ day $^{-1}$.

Intermediate dose isradipine $(n=5)$ : isradipine.

$1 \mathrm{mg} \mathrm{kg}^{-1}$ day $^{-1}$. day $^{-1}$

High dose isradipine $(n=5)$ : isradipine $4 \mathrm{mg} \mathrm{kg}^{-1}$

Hypercholesterolemic animals (pretreated and non pretreated).

Control group $(n=10)$ : cholesterol-rich diet.

Low dose lacidipine $(n=10)$ : cholesterol-rich diet+lacidipine $1 \mathrm{mg} \mathrm{kg}^{-1}$ day $^{-1}$.

Intermediate dose lacidipine $(n=10)$ : cholesterolrich diet+lacidipine $3 \mathrm{mg} \mathrm{kg}^{-1}$ day $^{-1}$

High dose lacidipine $(n=10)$ : cholesterol-rich diet+lacidipine $10 \mathrm{mg} \mathrm{kg}^{-1} \mathrm{day}^{-1}$

In both $\mathrm{NC}$ and $\mathrm{HC}$ animals the daily doses of the drugs were given in the morning (at 08:00 h) each mixed in $20 \mathrm{~g}$ of food pellets. Normal chow, up to $150 \mathrm{~g}$, was added after all medicated diet was eaten (usually within 30 minutes). For HC animals $1 \%$ cholesterol-rich diet was administered daily. In some rabbits HC diet and lacidipine-treatment started 8 weeks before the surgical insertion of the collar $(n=5$ for each dose) (HC60), while other animals ( $n=5$ for each dose) received cholesterol and lacidipine from the same day of the collar positioning (HC15). Records of food intake did not show any significant difference among the groups or within the groups. The doses here utilized did not affect arterial blood pressure. Animals had free access to water and were kept in a $12 \mathrm{~h}$ light-dark cycle. Total serum cholesterol was measured by a standard enzymatic procedure.
Neointimal hyperplasia induction and evaluation

Intimal hyperplasia was mechanically induced in one carotid artery, after the anesthesia of rabbits by intramuscular injection of $5 \mathrm{mg} \mathrm{kg}^{-1}$ xylazine and $35 \mathrm{mg} \mathrm{kg}^{-1}$ ketamine. Animals were then placed in dorsal recumbency. A neck midline incision was made and both carotid arteries were surgically exposed. A non occlusive, biologically inert, soft, and hollow Silastic $^{\mathrm{R}}$ collar was positioned around both carotids. The collar was $1.5 \mathrm{~cm}$ in length and it touched the artery circumference at two points $1 \mathrm{~cm}$ apart. In the sham arteries the collar was removed just before carotids were repositioned and the wounds were sutured. Animals were killed 2 weeks after the collar placement. All animals were given a lethal dose of sodium pentobarbital (65 mg kg-1 i.v.), and the vasculature was perfused with $0 \cdot 1 \mathrm{~mol} \mathrm{l}^{-}$phosphate-buffered-saline (PBS) for 10 minutes. Animals were then perfusion-fixed for another 20 minutes with $3 \%$ glutaraldehyde buffered with $0 \cdot 1 \mathrm{~mol} \mathrm{l}^{-} \mathrm{PBS}$ at a pressure of $100 \mathrm{~mm} \mathrm{Hg}$. Both carotid arteries were retrieved, paraffin embedded and stained with hematoxylin/eosin. At least 600 cross sections $(5 \mu \mathrm{m})$ were cut for each artery. Neointimal formation was measured by light microscopy and expressed as the ratio between the cross-sectional thickness of intimal and medial tissue. Intimal/Medial (I/M) ratios were calculated to normalize the data. The value of $\mathrm{I} / \mathrm{M}$ obtained from each animal is the mean of at least 1000 measurements performed on at least 10 sections $[19,20]$.

\section{Statistics}

Group data are expressed as means \pm sD. Statistical comparison of all numerical data between groups were performed by ANOVA. A $P$-value $<0.05$ was taken as statistically significant. Where statistically significant differences were established between groups further comparison for homogeneity means was made by using a Post Hoc Duncan's multiple range test. All statistical calculations were performed by CSS Software (Statsoft, USA).

\section{RESULTS}

There were no significant differences in the baseline body weight among groups of animals examined. Blood pressure values didn't change in all animals under treatment. Serum cholesterol values increased with cholesterol feeding in hypercholesterolemic rabbits in a time-dependent manner with a similar trend in all animals (data not shown).

\section{Normocholesterolemic animals}

The effectiveness of the periarterial insertion of the collar in inducing intimal carotid thickening was firstly assessed in control animals. A marked increase in intimal thickness was evident in the carotids with 


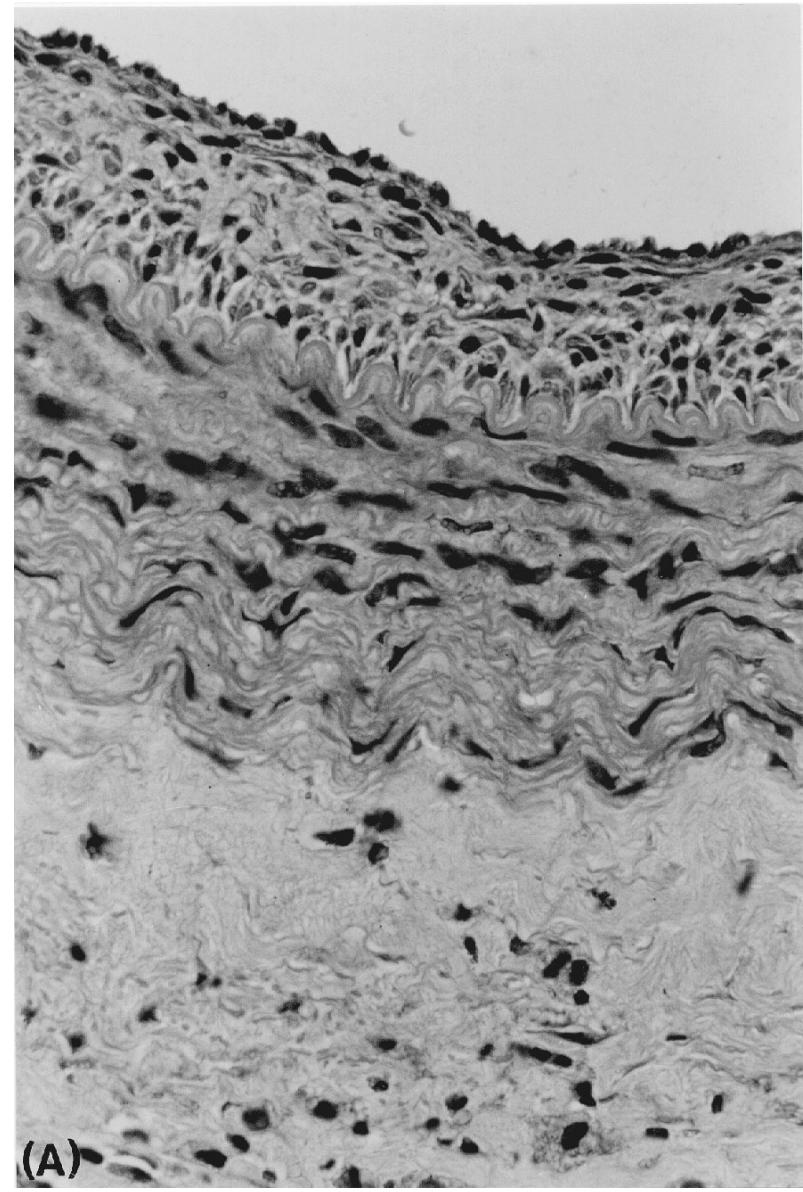

Fig. 1a.

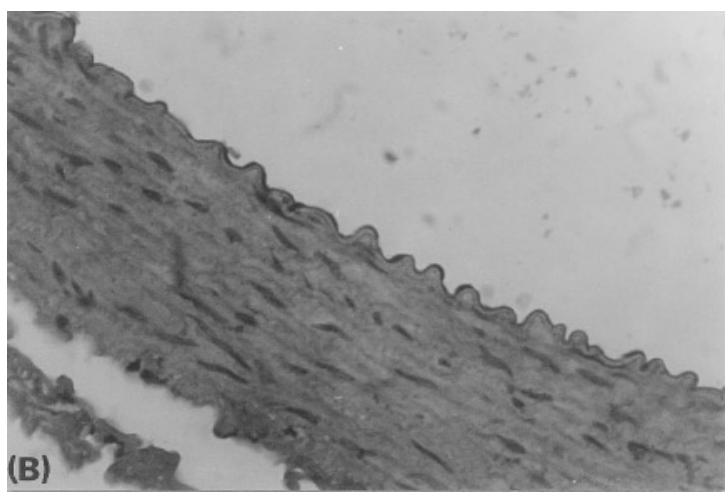

Fig. 1 .

collar [Fig. 1(A)], whereas the sham-operated arteries did not show thickening of the intima either in positive control or drug-treated rabbits [Fig. 1(B)]. The mean value of the I/M ratio in the collar arteries of the control group $(n=5)$ was almost twenty-fold greater $(0.53 \pm 0 \cdot 18)$ than in the sham group $(n=20)(0.03 \pm$ $0 \cdot 02)$. The intimal thickening, covered by the endothelial monolayer, was mostly cellular even in the presence of extracellular matrix [Fig. 1(A)]. Light microscopic observation of the sham tissue confirmed the presence of endothelial cells and the absence of

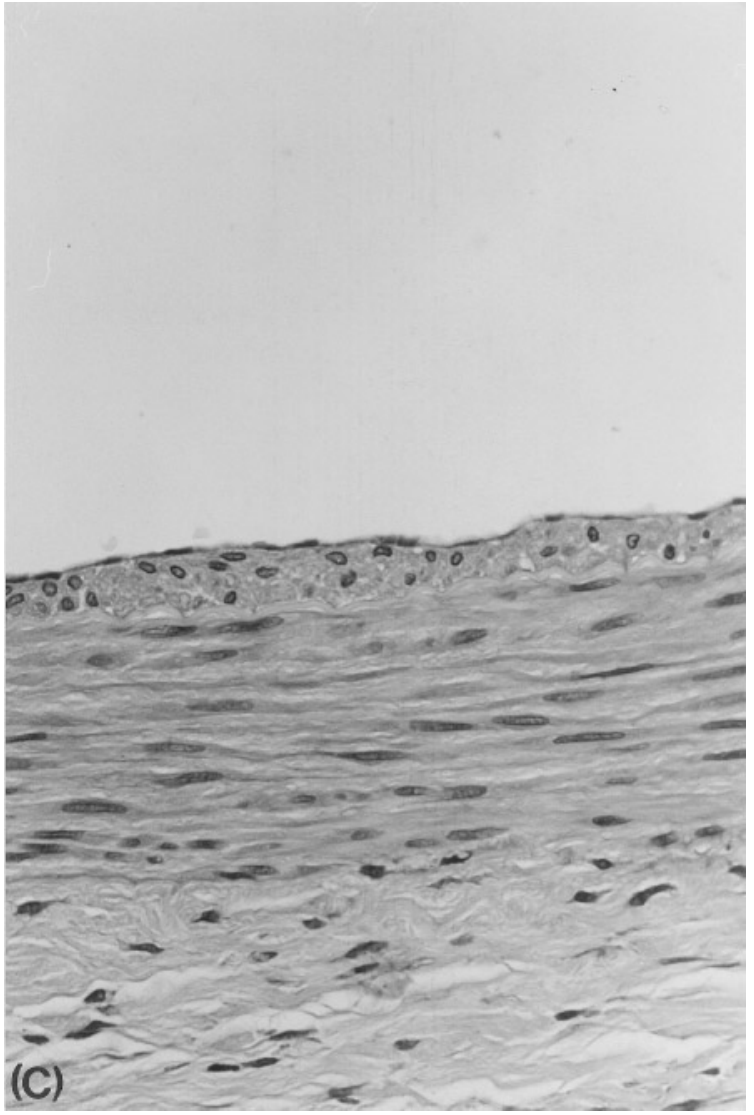

Fig. 1c.

Fig. 1. Microscopic views of tranverse sections $(5 \mu \mathrm{m}$ thick) of carotid arteries in normocholesterolemic rabbits 15 days after collar placement. (a) Collar carotid artery from a control rabbit showing a marked neointimal hyperplasia (296 $\times$ ). (b) Sham-operated artery without neointimal thickening (196×). (c) Collar carotid artery from a isradipine-treated rabbit $\left(1 \mathrm{mg} \mathrm{kg}^{-1} \mathrm{day}^{-1}\right)(296 \times)$.

intimal thickening [Fig. 1(B)]. In all drug-treated animals a reduction of neointimal thickening, detectable as fewer intimal cell layers, was evident. Figure 1(C) reports a typical transverse section obtained from isradipine-treated animals (intermediate dose). Isradipine at all concentrations significantly reduced the $\mathrm{I} / \mathrm{M}$ ratio when compared with the positive-control-group of NC animals $(0 \cdot 14 \pm 0.03,0 \cdot 12 \pm 0 \cdot 02,0 \cdot 1 \pm 0.02$ for the $0 \cdot 5,1$ and $4 \mathrm{mg} \mathrm{kg}^{-1}$ day $^{-1}$ doses respectively). This effect is summarized in Fig. 2.

\section{Hypercholesterolemic animals}

Neointimal formation in hypercholesterolemic rabbits was greater than that observed in normocholesterolemic animals [19, 20], suggesting a detrimental effect of hypercholesterolemia on this type of lesion. In control rabbits $\mathrm{I} / \mathrm{M}$ ratio was $1 \cdot 1 \pm 0 \cdot 14$ and $0 \cdot 71 \pm$ $0 \cdot 15$ after 8 weeks and 2 weeks of cholesterol feeding, respectively. In this neointimal hyperplasia, mostly cellular, lipid depositions were also present [Fig. 3(A)]. Arteries without collar did not show any morphological change and were exactly comparable with 


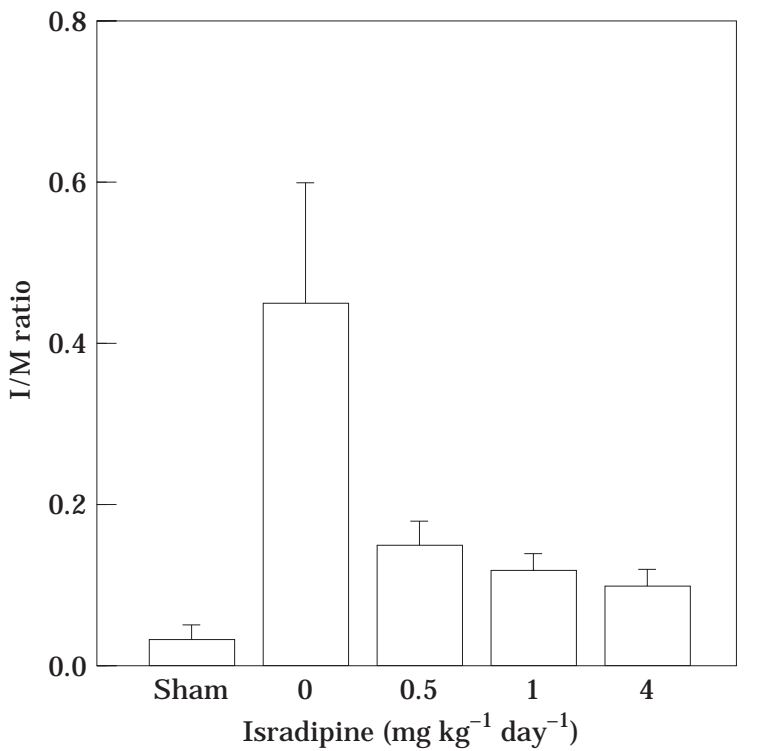

Fig. 2. Bar graph of dose-dependent effect of isradipine on neointimal hyperplasia induced in normocholesterolemic rabbits.

NC sham arteries. Only in HC60 lacidipine-pretreated animals a dose-dependent inhibition of the intimal hyperplasia was observed $(0.47 \pm 0.02,0.4 \pm 0.09$, and $0.38 \pm 0.02$ for dose 1,3 , and $10 \mathrm{mg} \mathrm{kg}^{-1}$ day $^{-1}$ ) [Fig. 3(B)]. Starting the treatment on the same day of the collar placement, the inhibition of neointimal hyperplasia was much less evident $(0 \cdot 7 \pm 0 \cdot 15,0 \cdot 6 \pm 0 \cdot 18$, and

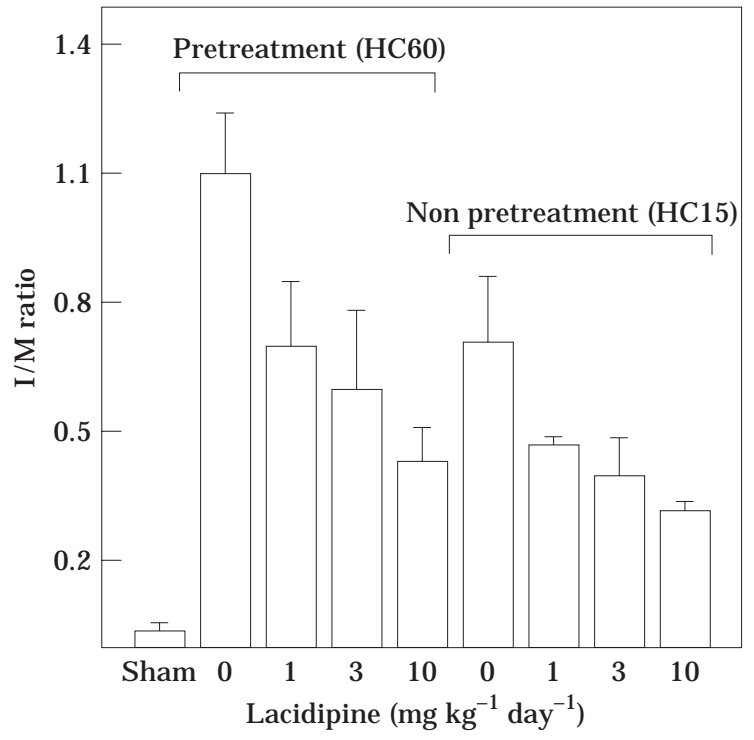

Fig. 4. Bar graph of dose-dependent effect of lacidipine on neointimal hyperplasia induced in pretreated and nonpretreated hypercholesterolemic rabbits.

$0 \cdot 43 \pm 0.08$ for dose 1,3 , and $10 \mathrm{mg} \mathrm{kg}^{-1}$ day $^{-1}$ ) (Fig. 4).

\section{DISCUSSION}

In the present investigation we quantitated the influence of two calcium antagonists of the dihydropiridine class (isradipine and lacidipine) on the development

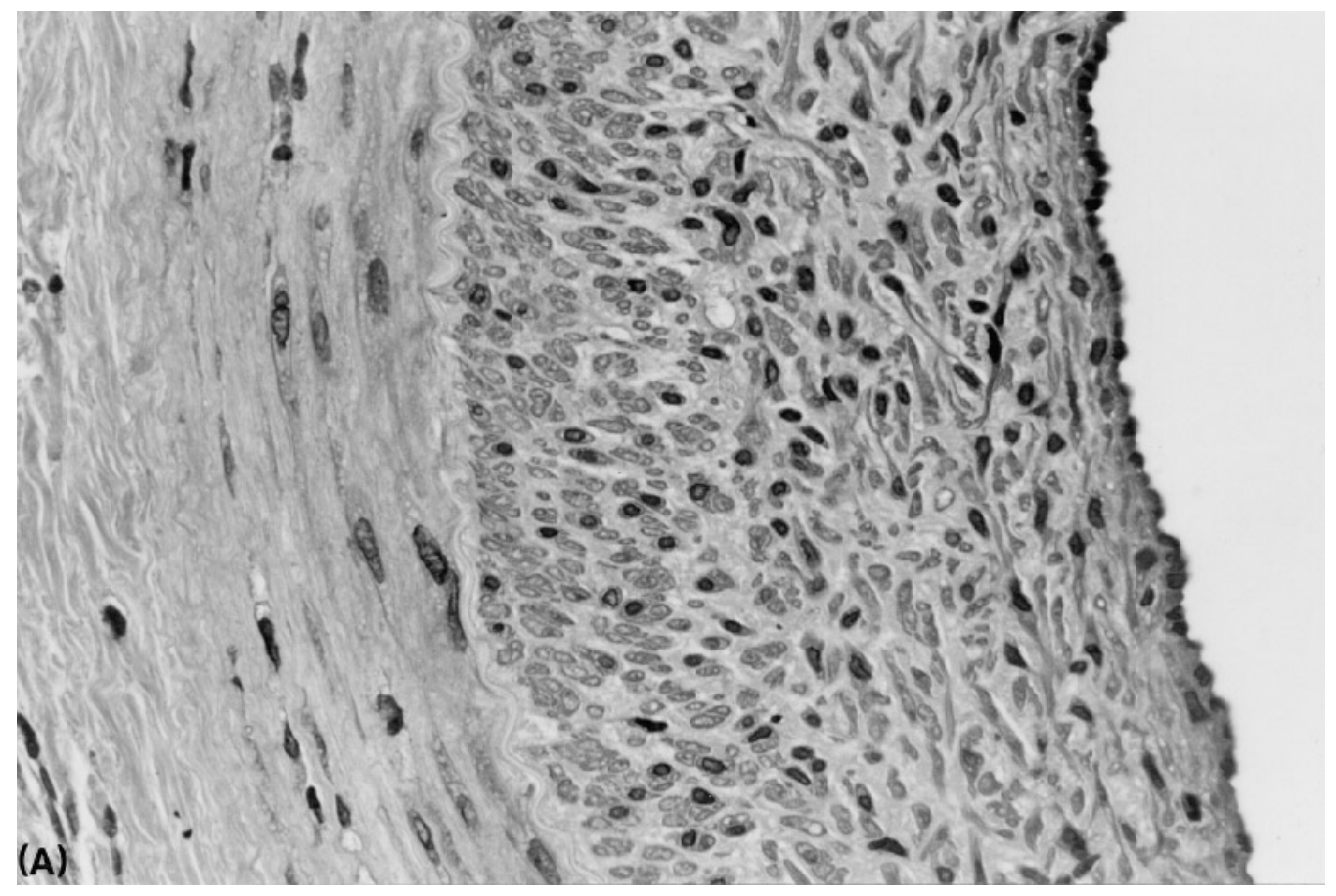

Fig. 3a. 
of an atherosclerotic lesion characterized mainly by smooth muscle cell accumulation. Administration of isradipine in NC animals resulted in a marked inhibition of these lesions, with a dose-dependent inhibitory effect on neointimal hyperplasia. These findings are consistent with the view that this dihydropyridine inhibits in vivo migration/proliferation of smooth muscle cells. Similar results were obtained in HC animals only with preventive treatment with lacidipine.

The increasing knowledge on the pathogenesis of atherosclerosis has prompted investigations into the possibility of direct pharmacological control of the pathological processes occurring in the arterial wall. Calcium antagonists are well established in the treatment of a number of cardiovascular disorders [21, 22]. Besides evidence that they reduce blood pressure, experimental and clinical data support the concept that $\mathrm{Ca}^{2+}$ antagonists may protect against structural changes occurring in the vessel wall during the progression of atherosclerosis [2, 23-25]. Several calcium-dependent processes contribute to atherogenesis, including lipid infiltration and oxidation, endothelial injury, chemotaxis and growth factor release, smooth muscle cell migration and proliferation [21].

Calcium antagonists modulate LDL cholesterol metabolism [26] and affect SMC migration and proliferation in vitro [2, 14, 27]. However, evidence is growing on the direct effect of calcium antagonists on intimal hyperplasia due to SMC migration and proliferation $[2,13]$. In this study we aimed at addressing whether dihydropyridine calcium antagonists could affect the development of this type of atherosclerotic lesion. Both isradipine and lacidipine, effectively reduced the extent of neointimal hyperplasia induced in these animals, independently of blood pressure variations. At doses as low as $1 \mathrm{mg} \mathrm{kg}^{-1}$ day $^{-1}$ both drugs inhibited neointimal formation by about $50 \%$. The lack of inhibition of I/M ratio in non pretreated lacidipine $\mathrm{HC}$ animals suggests that lacidipine should be present at the site of the lesion before its surgical induction since drug preferentially interferes with early atherogenic processes.

Results on this proliferative lesion strongly support the in vitro observation that lacidipine can affect directly SMC migration and/or proliferation, a property shared with other calcium antagonists [27, 28]. Lesion cellularity could be, on the other hand, modulated by enhanced programmed cell death (apoptosis), a phenomenon particularly evident at early stages in this model (1-3 days after collar positioning, data not shown). This issue is currently under investigation. Another possibility could be represented by the blockade of $\mathrm{Ca}^{2+}$-dependent processes related to the massive leukocyte infiltration observed at early stages in this model (data not published). This possible indirect inhibition of smooth muscle cell migration/proliferation should be investigated considering the effect of lacidipine in pretreated animals killed sooner (1, 3, 7 days) after collar placement.

In conclusion, the present in vivo findings show

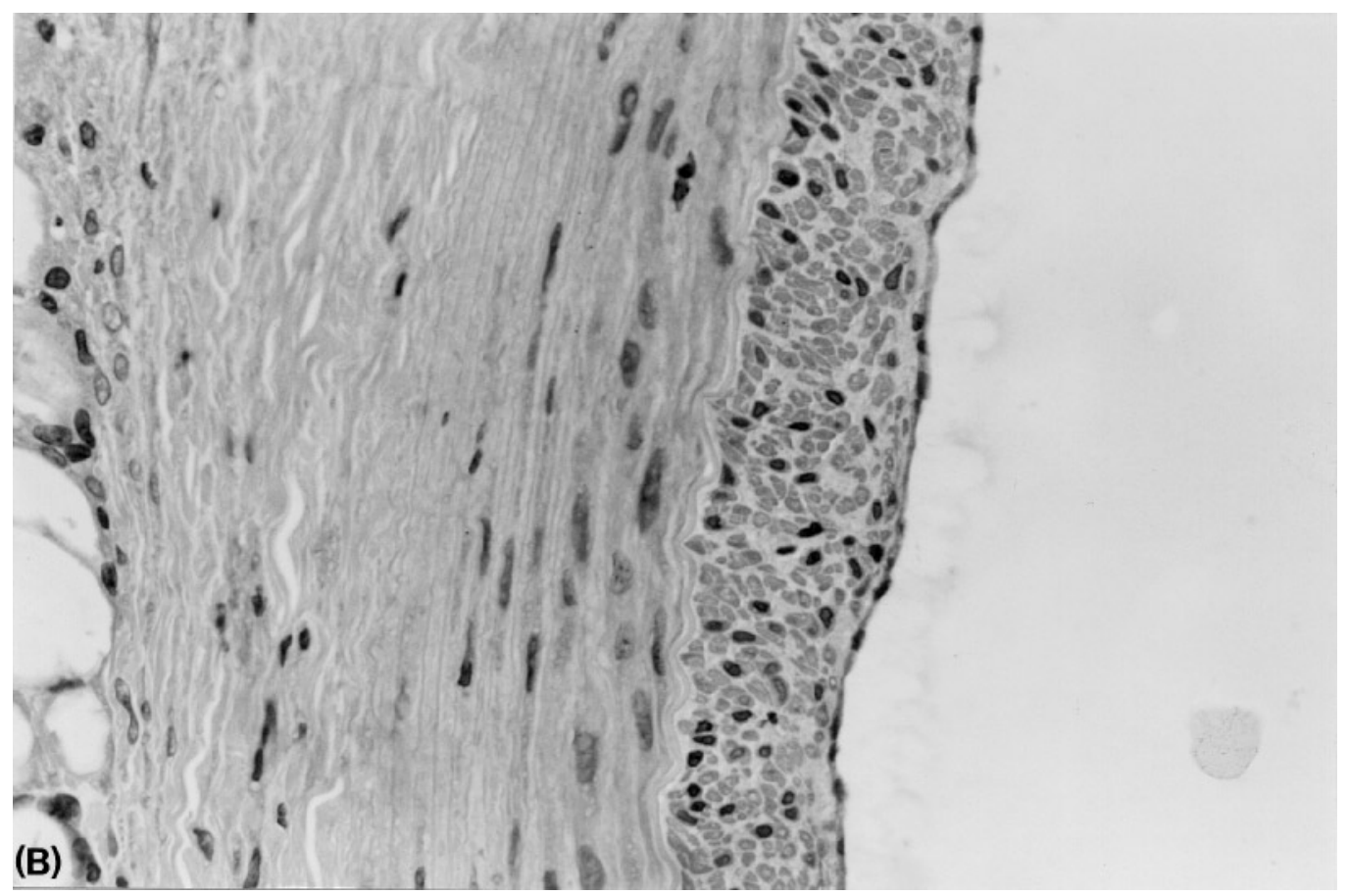

Fig. 3b.

Fig. 3. Microscopic views of tranverse sections ( $5 \mu \mathrm{m}$ thick) of carotid arteries in hypercholesterolemic rabbits 15 days after collar placement. (a) Collar carotid artery from a control rabbit showing a marked neointimal hyperplasia (360×). (b) Collar carotid artery from a lacidipine pretreated rabbit $\left(1 \mathrm{mg} \mathrm{kg}^{-1}\right.$ day $\left.^{-1}\right)(360 \times)$. 
that calcium antagonists exert a protective effect on the vessel wall, interfering with different atherosclerotic processes. These drugs may be effective in controlling abnormal vascular smooth muscle growth and migration, thus representing useful tools for preventing the disease.

\section{ACKNOWLEDGEMENTS}

We would like to thank Mrs Laura Mozzarelli for her skillfullness and rapidity in typing the manuscript. This research was partially supported by MURST (Italy), MPI (Italy) and CNR target project 'Apoptosis and cell cycle'.

\section{REFERENCES}

1. Ross R. The pathogenesis of atherosclerosis: a perspective for the 1990s. Nature 1993; 362: 801-9.

2. Jackson CL, Schwartz SM. Pharmacology of smooth muscle cell replication. Hypertension 1992; 20: 713-36.

3. Popma JJ, Califf RM, Topol EJ. Clinical trials of restenosis after coronary angioplasty. Circulation 1991; 84: $1426-36$.

4. Bernini F, Catapano AL, Corsini A, Fumagalli R, Paoletti R. Effects of calcium antagonists on lipids and atherosclerosis. Am J Cardiology 1989; 64: 129I-34.

5. Bernini F, Corsini A, Raiteri M, Soma MR, Paoletti R. Effects of lacidipine on experimental models of atherosclerosis. J Hypertension 1993; 11(Suppl. 3): S61-6.

6. Lichtor T, Davis HR, Vesselinovitch D, Mullan S. Suppression of atherogenesis by nifedipine in the cholesterol-fed rhesus monkey. Appl Pathol 1989; 7: 8-18.

7. Henry PD. Calcium channel blockers and atherosclerosis. J Cardiovasc Pharmacol 1990; 16: S12-15.

8. Kunjara-Na-Ayudhya R, Thomson AB, Kappagoda CT. Effect of Isradipine on the formation and regression of fatty streaks in cholesterol fed rabbits. Cardiovasc Res 1994; 28: 1089-95. (Abstract).

9. Keogh AM, Schroeder S. A review of calcium antagonists and atherosclerosis. J Cardiovas Pharmacol 1990; 16: $\mathrm{S} 28-35$.

10. Weinstein DB, Heider JG. Antiatherogenic properties of calcium antagonists: state of the art. Am J Med 1989; 86(Suppl. 4A): 27-32.

11. Catapano AL, Maggi FM, Cicerano V. The antiatherosclerotic effect of anipamil in cholesterol-fed rabbits. Ann NY Acad Sci 1988; 522: 519-21.

12. Soma MR, Parolini C, Donetti E, Fumagalli R, Paoletti $\mathrm{R}$. Inhibition of isoprenoid biosynthesis and arterial smooth muscle cell proliferation. $J$ Cardiovasc Pharmacol 1995; 25(Suppl. 4): S20-4.

13. Soma MR, Donetti E, Seregni R, Barberi L, Fumagalli R, Paoletti R, Catapano AL. Effect of lacidipine on fatty and proliferative lesions induced in hypercholesterolemic rabbits. Br J Pharmacol 1996; 118: 215-19.

14. Nomoto A, Mutoh S, Hagihara H, Yamaguchi I. Smooth muscle cell migration induced by inflammatory cell products and its inhibition by a potent calcium antagonist, nilvadipine. Atherosclerosis 1988; 72: 213-19.

15. Daugherty A, Rateri DL, Schonfeld SB. Inhibition of cholesteryl ester deposition in macrophages by calcium entry blockers: an effect dissociable from calcium entry blockade. Br J Pharmacol 1987; 91: 113-18.

16. Bernini F, Bellosta S, Didoni G, Fumagalli R. Calcium antagonists and cholesteryl ester metabolism in macrophages. J Cardiovas Pharmacol 1991; 18 (Suppl. 10): S42-5.

17. Schmitz G, Robenek H, Beuck M, Krause R, Schurek A, Niemann R. Ca ${ }^{2+}$ antagonists and ACAT inhibitors promote cholesterol efflux from macrophages by different mechanisms. Arteriosclerosis 1988; 8: 46-56.

18. Stein O, Stein Y. Effect of verapamil on cholesteryl ester hydrolysis and reesterification in macrophages. Arteriosclerosis 1987; 7: 578-84.

19. Soma MR, Donetti E, Parolini C, Mazzini G, Ferrari C, Fumagalli R. HMG CoA reductase inhibitors: in vivo effects on carotid intimal thickening in normocholesterolemic rabbits. Arterioscl Thromb 1993; 13: 571-8.

20. Soma MR, Donetti E, Parolini C, Sirtori CR, Fumagalli R, Franceschini G. Recombinant apolipoprotein AIMilano dimer inhibits carotid intima thickening induced by perivascular manipulation in rabbits. Circ Res 1995; 76: 405-11.

21. Nayler WG. Pharmacological aspects of calcium antagonism. Short term and long term benefits. Drugs 1993; 46: 40-7. (Abstract).

22. Waters D, Lesperance J. Calcium channel blockers and coronary atherosclerosis: from the rabbit to the real world. Am Heart Journal 1994; 128: 1309-16. (Abstract).

23. Nayler WG. Calcium channels and their involvement in cardiovascular disease. Biochem Pharmacol 1992; 43: 39-46.

24. Lichtlen PR, Nellessen U, Rafflenbleu W, Hecker H. International nifedipine trial on antiatherosclerotic therapy (INTACT). Cardiovasc Drug Ther 1987; 1: 71-9.

25. Parmley WW. Calcium channel blockers and atherogenesis. Am J Med 1987; 82: 3-8.

26. Bernini F, Allorio M. Calcium antagonists and low density lipoprotein receptors. Ann NY Acad Sci 1988; 522: 390-8.

27. Corsini A, Raiteri M, Dimitri V, Donetti E, Soma MR, Bernini F. Vascular smooth muscle and atherosclerosis: role of isoprenoids and calcium antagonists. $J$ Vasc Med Biol 1994; 5: 111-19.

28. Soma MR, Bernini F, Corsini A, Paoletti R. Calcium antagonists in atherosclerosis: focus on lacidipine. Res Clin Forums 1994; 16: 47-51. 